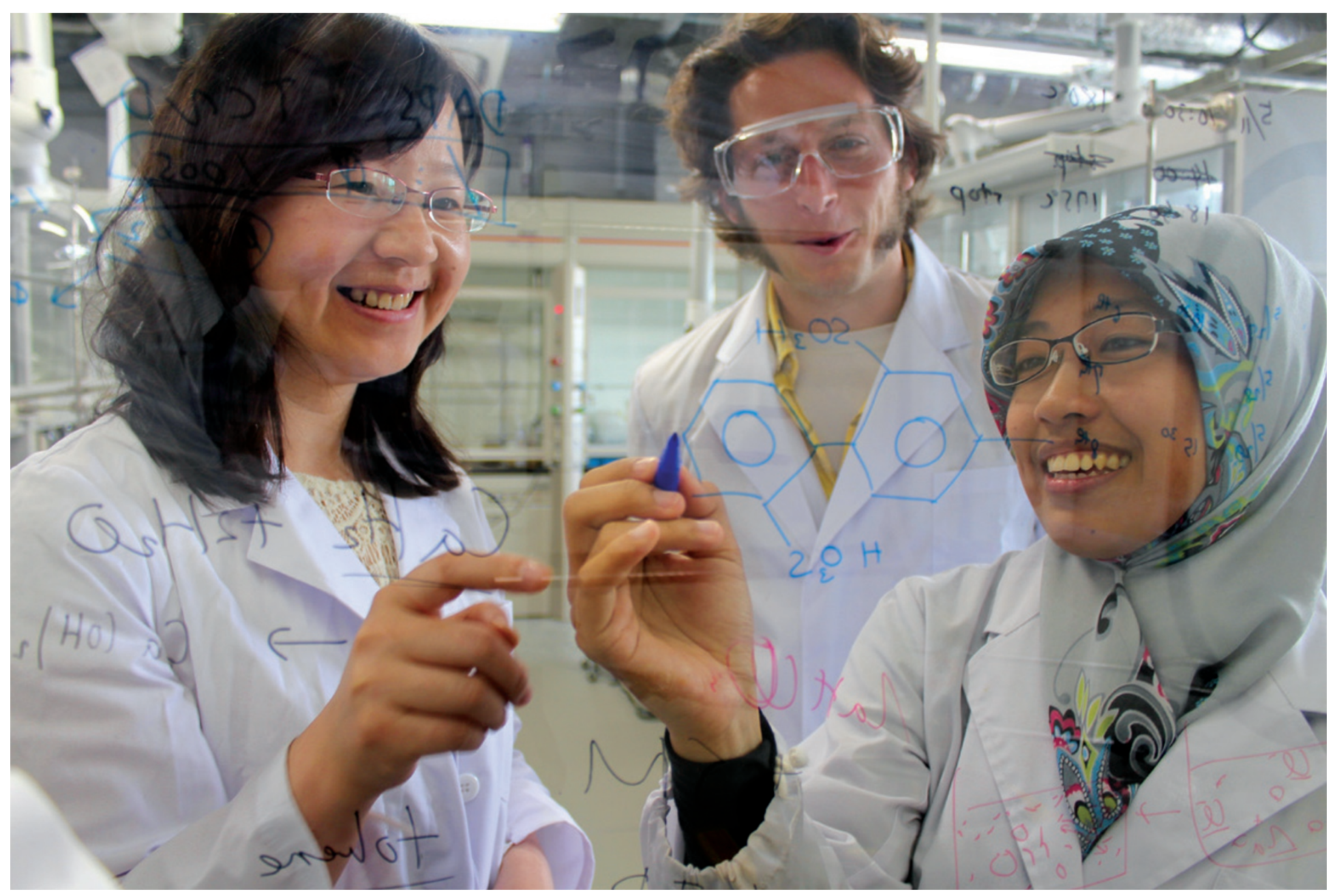

Researchers working on electrochemical energy conversion search for fuel cell breakthroughs at the $\mathrm{I}^{2} \mathrm{CNER}$ at Kyushu University.

\title{
FLAGGING FORTUNES INVITE REFORM
}

Japan's quest to retain its status as a global research leader by enticing foreign students
and faculty is the right response, say observers, but efforts are yet to have an impact.

\section{BY ICHIKO FUYUNO}

$\mathrm{T}$ he landlocked former Soviet republic of Uzbekistan seems an odd choice of 1 location for a Japanese education fair, but, in November 2015, representatives from seven leading Japanese universities travelled to Tashkent, the Uzbek capital, for their fifth annual event.

Presented by Nagoya University, it drew hundreds of local students interested in the opportunity to study at prestigious Japanese institutions without having to speak the language.

About 100 Uzbek students come to Japan every year, including about 40 to Nagoya, but Yoshihito Watanabe, the vice president of Nagoya University, would like to attract more.

"Their interest in Japanese education is probably the highest among other countries where we organize similar events," says Watanabe, who is in charge of international education at his university.

From France and the United Kingdom to China, India and Thailand, Nagoya University and other leading Japanese universities hold similar promotional events around the world. They aim to strengthen communication with education officials and local students, and entice them to study in Japan.

This strategy responds partly to a sense among the Japanese research community that its research output and impact has stagnated in recent years. While Japan ranked fifth in the Nature Index in 2015, the country's performance in the database

"About 100 students from Uzbelistan come to Japan everyyear, including about 40 to Nagoya." fractional count (WFC) - has fallen 12\% (see Top 10 Index performers). The performances of the United States and France have also declined.

After decades of keeping universities insular, Japan has realized that diversity and collaboration are essential to producing world-class science and research. To revive Japan's academic competitiveness, the Ministry of Education, Culture, Sports, Science and Technology (MEXT) has been pushing its higher education sector to attract more foreign staff and students. Simultaneously, it has been implementing reforms to make its research environment more competitive with the best research universities in the world. "Internationalization changes the internal structure of universities, which makes them more flexible and on par with global norms," says Petros Sofronis, director of the WPI (World Premier International Research Center Initiative) International Institute for Carbon-Neutral Energy Research ( $\left.{ }^{2} \mathrm{CNER}\right)$ at Kyushu University. 
“The Japanese government is doing the right 尖 thing," says Sofronis.

But many policy analysts and senior researchers say these efforts aren't enough. They say more reforms are needed to allow research institutions and universities to make decisions about their own structure. "If the government is really determined to raise the level of globalization, current strategies are insufficient," says Hiroshi Nagano, visiting fellow at the Japan Science and Technology Agency, who is a specialist in international science polices.

\section{DECLINING TREND}

For more than a decade, the Japanese government has tightened its annual budget for science amid the country's weak economy and growing social welfare demands. The 2016 budget for science and technology is set at 3.45 trillion yen, down 6.4\% from its peak in 2012 .

The government's R\&D investment accounted for $19.5 \%$ of the country's total $\mathrm{R} \& \mathrm{D}$ spend in 2013, the lowest among major countries including China, South Korea and the United States.

The president of Suzuka University of Medical Sciences, Nagayasu Toyoda, who observes Japanese science policies closely, says the effect has been "deteriorated support for fundamental research activities, the foundation of our country's strength."

And while the Japanese government, since 2005, has increased the value of competitive grants awarded to scientists for research projects, it has slashed the key funding pool that national universities and research institutions rely on to make themselves more competitive, known as Management Expenses Grants.

It's not just within the Nature Index that Japan's ranking has slipped. According to a recent report by the National Institute of Science and Technology Policy (NISTEP), the number of Japanese papers cited in the top 1\% of all journal articles published between 2011 and 2013 fell to seventh in the world, down from fourth a decade ago.

\section{OPENING UP}

The Japanese government's efforts to open up higher education are not new, but they have accelerated in the past few years. While the budget for science and technology has fallen, the money available for higher education institutions to globalize has surged from 1.9 billion yen in 2006 to 9.34 billion yen in 2016 . Between 2009 and 2013, the MEXT established the Global 30 project, funding 13 leading universities to create degree courses in English that would attract foreign students amid intensifying recruitment competition with other countries. As the number of courses taught in English at these universities grew from a handful in 2009 to more than 300 now, the number of overall overseas students grew from 23,083 in 2009 to more than 28,000 by 2013 , including

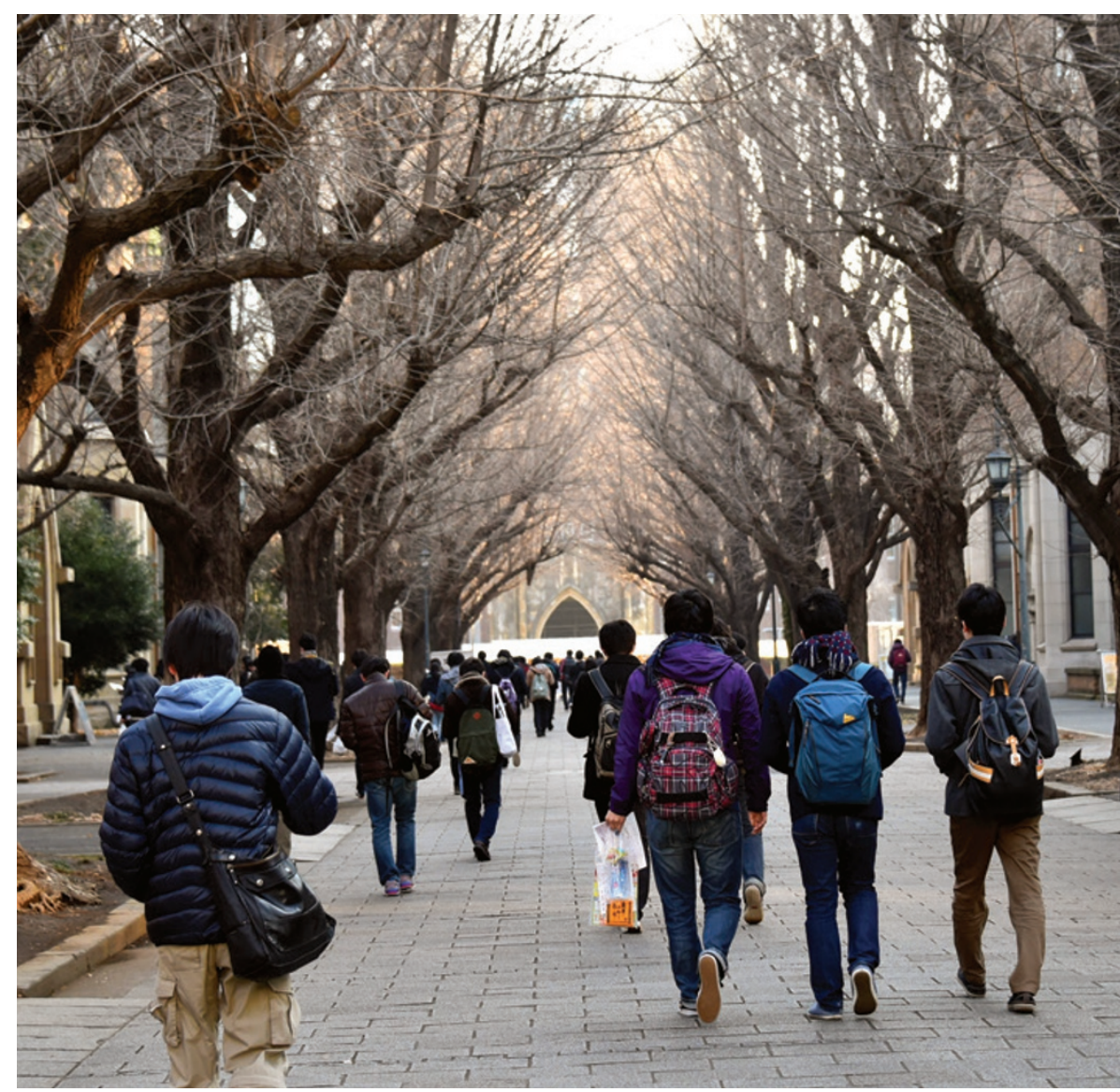

Prospective students head for an entrance examination at The University of Tokyo's Hongo campus.

\section{THE TOP 10 PERFORMERS IN THE NATURE INDEX IN 2015}

From 2012 to 2015 , these 10 countries have contributed the most to the publications tracked by the Nature Index. The WFC of most nations has stagnated or declined.

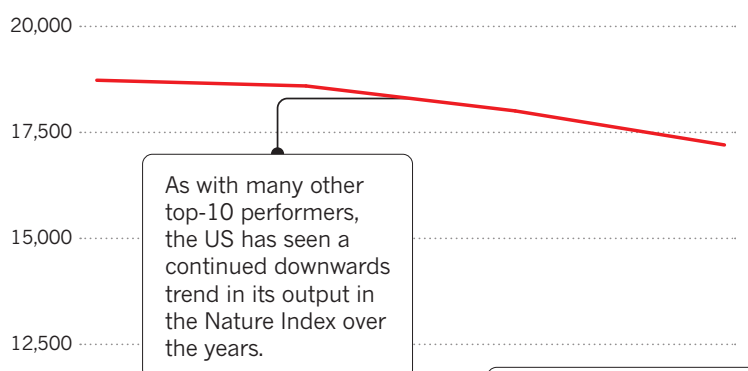

China has continued to \begin{tabular}{l|l}
10,000 & raise its output in the
\end{tabular} Nature Index, slowly widening the gap between itself and the rest of the pack.

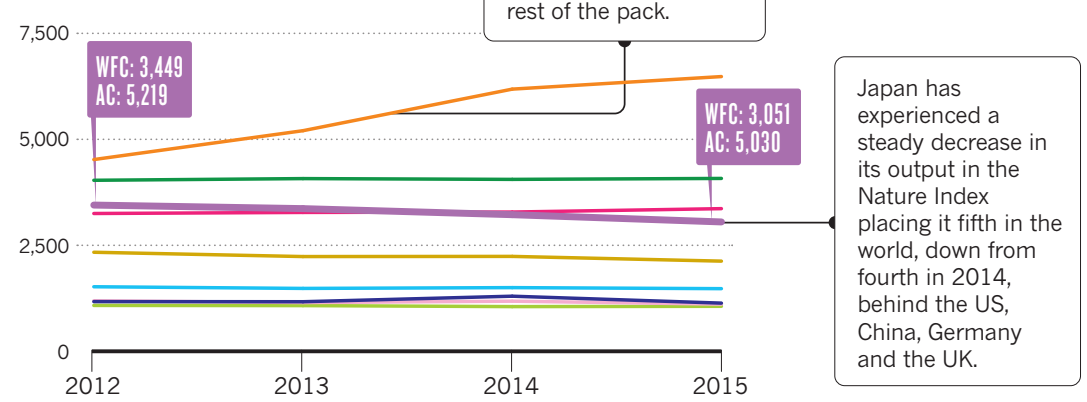

\section{KEY \\ United States \\ China \\ Germany \\ United Kingdom \\ Japan \\ - France \\ - Canada \\ Switzerland \\ South Korea \\ Italy}

Weighted fractional count (WFC) is a metric that apportions credit for each article according to the affiliations of the contributing authors. Article count (AC) is the that have at least one author from that country or institution. 
those enrolled at short-term programmes and other non-Global 30 courses. But this modest increase in international students cost Japanese taxpayers 14.7 billion yen over five years, and by 2013 the country's percentage of foreign students, $3.4 \%$, remained well below the OECD average of $9 \%$. The increase in foreign students is also yet to be reflected in the output of high-quality research for most Global 30 participants (see below).

\section{NEXT STEP}

While the Global 30 project succeeded in increasing the number of university courses offered in English, the MEXT launched another programme in 2014 to catapult more Japanese universities into the world's top 100 institutions. The Top Global University Project, often referred to as the Super Global University programme, funds 37 universities to change their organizational structures, partly to deepen ties with international institutes. Thirteen 'Type A' universities - many of which are among the top ten institutions in the Nature Index in Japan in 2015 - will receive up to 500 million yen a year until 2023 to become a top 100 university in rankings such as the Times Higher Education list. Many Type A members are striving to create joint degrees with top-level overseas institutions. In April 2015, Tohoku University established the world's first graduate programme in spintronics in collaboration with Johannes Gutenberg-Universität Mainz. The spintronics course fits with Japan's strength in physical sciences, evidence of which is seen in the Nature Index (see Subject Split, S102).

Another 24 'Type B' institutions will be given up to 300 million yen to use their unique strengths to contribute to local economies.

Perhaps Japan's most successful programme to promote internationalization is the WPI, which launched in 2007 and comprises nine institutes. The official language of these centres is English and an average $40 \%$ of researchers are from abroad. WPI institutes accounted for $4.63 \%$ of the world's most highly cited papers between 2007 and 2013, the third largest contribution after the Rockefeller University and the Massachusetts Institute of Technology (MIT).

But the executive director of RIKEN, Yoichiro Matsumoto, says there are few indicators to assess the success of these programmes. "The government evaluates the impact of programmes like Global 30 only by numbers. But we have to create new measures to assess how universities bring competitive personnel into the global society," says Matsumoto.

\section{FUNDAMENTALPROBLEMS}

Charles Yokoyama, director of research administration at the RIKEN's Brain Science Institute (BSI), says that despite Japan's efforts to attract overseas staff and students, it's hard for the country to keep up.

"Globalization activities are slower than they can or should be to keep up with global competition," he says. The RIKEN BSI is one of the most international institutions in Japan yet only a few postdocs are trained, or awarded faculty positions at elite US universities. The pool of talented researchers largely bypasses Japan, says Yokoyama.

Hiring excellent researchers is key to attracting top-level students from abroad, but "Japan can be no match for the United States and other major countries so far in terms of the level of salaries and welfare packages for families," adds Takaaki Kajita, director of the Institute for Cosmic Ray Research at the University of Tokyo.

While Japan may struggle to compete with other nations in terms of recruitment, Japanese researchers are reaching out to partner with their global peers. Between 2014 and 2015, Japan's collaborations with China, the United Kingdom, France and Germany grew. Its partnerships with the United States also increased, an upsurge to a three-year decline (see Japan's top partnerships).

Shizuo Akira, director of the WPI Immunology Frontier Research Center at Osaka University, says many young Japanese researchers are unwilling to move labs or go abroad for postdoc positions and miss opportunities to learn from different leaders. Akira, one of the world's most cited immunologists, says young Japanese researchers are reluctant to move as competition for positions in Japan is intense after returning from abroad. "Unless we establish a practical career path that presents young fellows as visibly prominent scientists on the global stage, there is little hope for the future of Japanese science."

The government is aware of these issues and is implementing various measures to strengthen ties with overseas collaborators.

\section{GLOBAL 30 PROJECT UNIVERSITIES IN THE NATURE INDEX}

The MEXT Global 30 project funded 13 leading universities to create degree courses in English that would attract foreign students.

The courses surged from a handful in 2009 to more than 300 now.

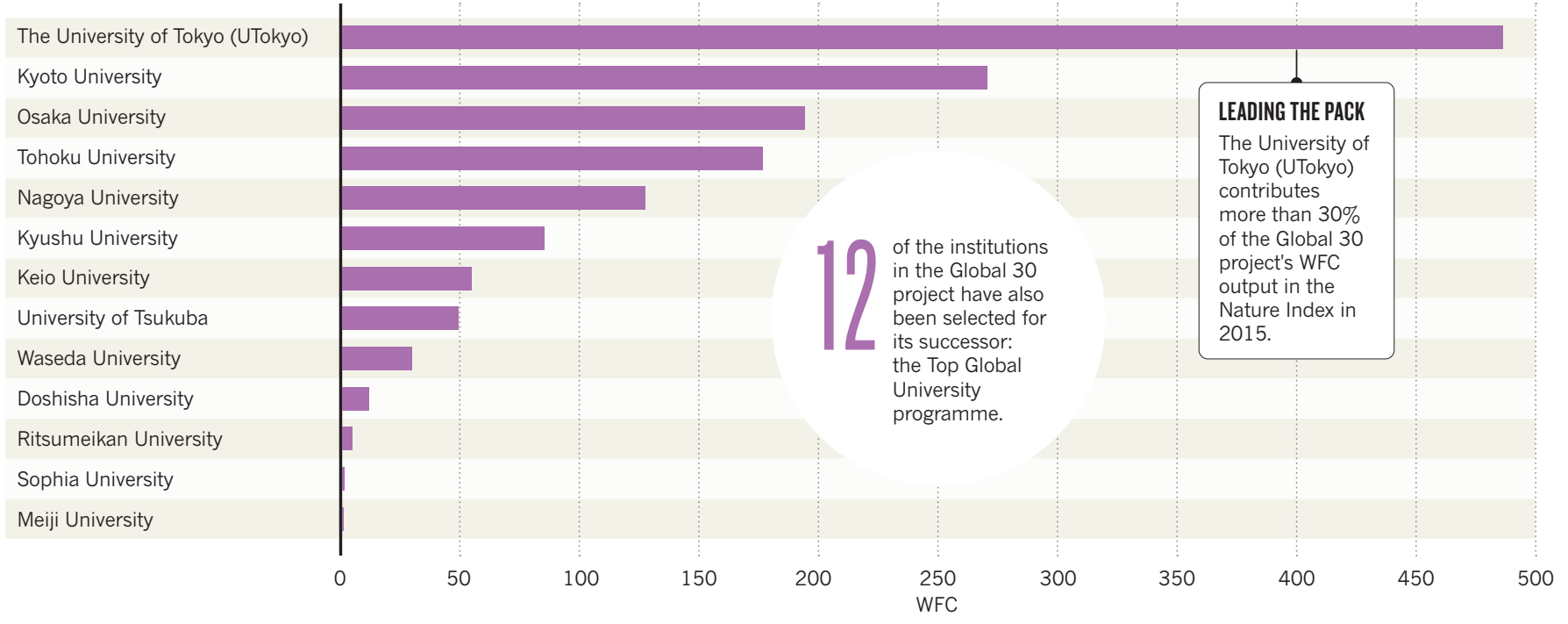


The MEXT is in the process of revising Japan's biggest competitive grant, the Grants-inAid for Scientific Research, so it can provide greater support for joint international research. In addition, the ministry set aside 5.6 billion yen this year to accelerate intellectual exchange, allowing about 520 young Japanese researchers to work abroad for two years, and 1,100 overseas researchers to come to Japan.

But Nagano worries these measures are relatively small due to the government's tight science budget, and many have not led to a rise in Japan's rankings. "If Japan wants to raise its global ranking, we need to recruit good students. To do that, we need good faculty. But there are no measures that combine these two points," he says.

Meanwhile, Yokoyama observes that Japan's traditional solutions to globalize research often focus on the recruitment of international visitors such as students and junior faculty, but more basic reforms of domestic graduate programmes are needed for Japan to develop a globally competitive STEM (science, technology, engineering and mathematics) workforce.

"The level, approach and pace of globalization of Japan's graduate programmes have fallen short of elite global standards including the key issue of training in high-level English communication," he says.

Atsushi Sunami, the government's advisor for science policies at the National Graduate Institute for Policy Studies, says comprehensive reforms of national universities are currently underway to reorganize faculties, strengthen governance and review funding and personnel systems, but their effect will take time.
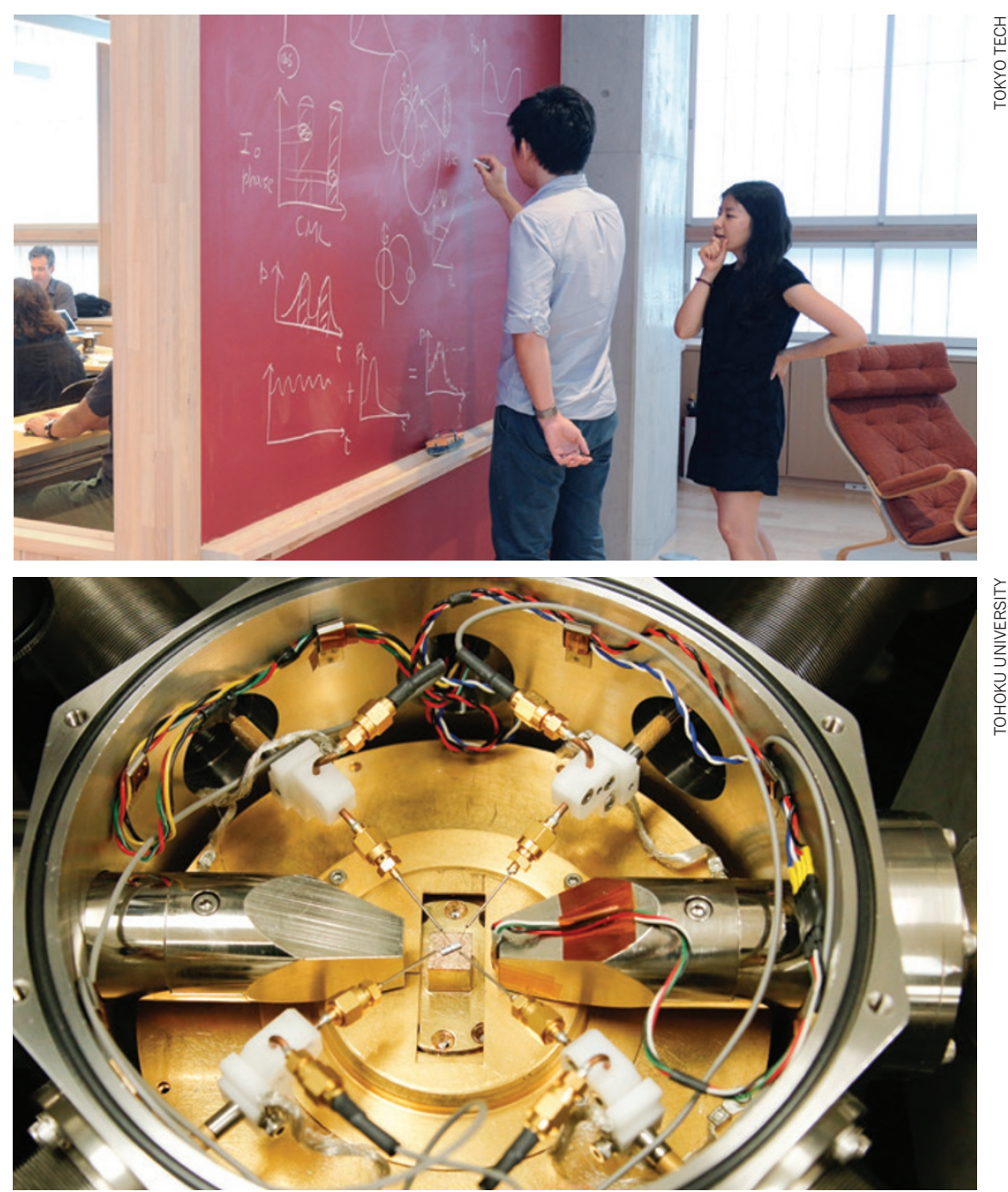

Top: Students work on a solution at the Earth Life Science Institute, a designated WPI centre. Bottom: A system for testing the properties of spintronics components at Tohoku University.

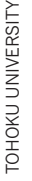

\section{JAPAN'S TOP PARTNERSHIPS}

Japan's most prolific collaboration partnerships are with the United States, Germany and China. The largest collaboration vith the United States has seen a slight decline, while partnerships with Germany and China have grown.

JAPAN-UNITED STATES

1,200
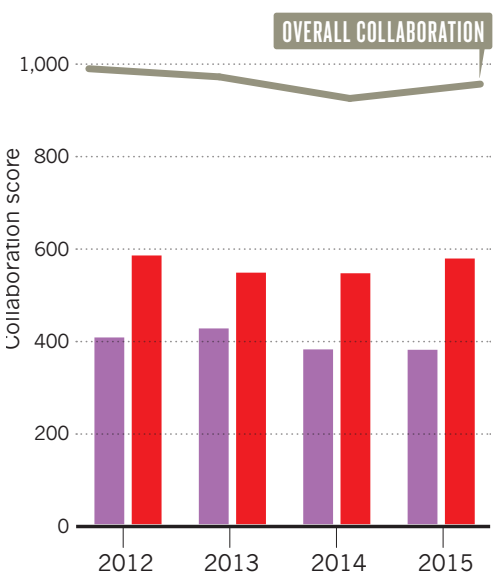

JAPAN-GERMANY
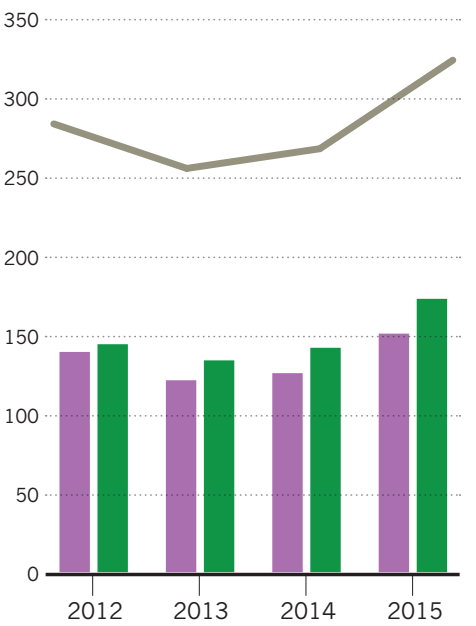

JAPAN-CHINA
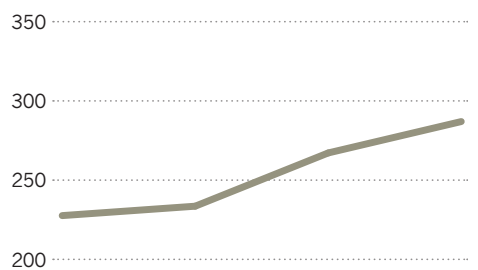

200

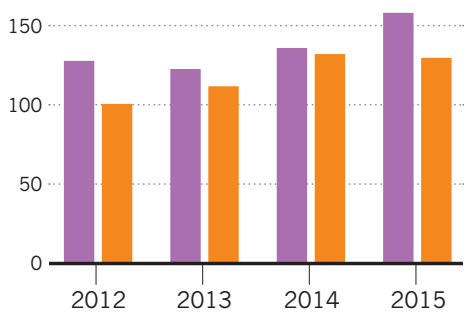

KEY

Contribution

to overall

collaboration

Japan

United States

Germany

China 